\title{
Periodontal and chronic kidney diseases: A modifiable association
}

\author{
Foujan Jabbarzadehkhoei', Soheila Bakhshandeh², Mahshid Namdari², Mina Pakkhesal, \\ Mohammad Hossein Khoshnevisan 2,4*
}

\author{
School of Dentistry, Shahid Beheshti University of Medical Sciences, Tehran, Iran. \\ ${ }^{2}$ Community Oral Health Department, School of Dentistry, Shahid Beheshti University of Medical Sciences, Tehran, Iran. \\ ${ }^{3}$ Community Oral Health Department, School of Dentistry, Golestan University of Medical Sciences, Gorgan, Iran. \\ ${ }^{4}$ Dental Research Center, Research Institute of Dental Sciences, School of Dentistry, Shahid Beheshti University of Medical Sciences, Tehran, Iran. \\ *Correspondence to: Mohammad Hossein Khoshnevisan (E-mail: khoshmh@gmail.com) \\ (Submitted: 12 November 2020 - Revised version received: 29 November 2020 - Accepted: 07 December 2020 - Published online: 26 February 2021)
}

\begin{abstract}
Objective The purpose of this study was to assess the relationship between periodontal diseases and chronic kidney disease (CKD) duration. Methods This descriptive cross-sectional study was conducted on referral CKD patients to a teaching hospital in 2017. Two instruments were used for data collection. The first one was a self-reported questionnaire regarding oral health status and patients' behaviors. The second questionnaire was used for the clinical assessment of oral health status.

Results Out of 192 patients, 46.9\% were male and 53.1\% female with a mean (SD) age of 51.9 ( \pm 15.1 ) years. The mean duration of CKD was 7.70 ( \pm 7.34 ) years. About $67.7 \%$ of patients experienced toothache in the past year. Also, $67.7 \%$ had gingival bleeding (BOP), 34.4\% had clinical attachment loss (CAL) $>4 \mathrm{~mm}$, and over $50 \%$ of patients had a pocket depth (PD) $>4 \mathrm{~mm}$. By controlling the patient's age, a direct correlation was detected between the duration of CKD and decayed, missing, and filled teeth index $(r=0.64, P<0.001)$. Moreover, the prolongation of the disease period was detected in patients with $C A L>4 \mathrm{~mm}(P=0.02)$. Likewise, a direct correlation was detected between the duration of CKD and the periodontal index $(r=0.48, P<0.001)$.

Conclusions Given the direct correlation between the periodontal conditions and duration of CKD, regular biannual dental visits are essential for CKD patients. All physicians are encouraged to include regular oral health checkups in the treatment protocol for CKD patients.

Keywords Periodontal disease; Chronic kidney disease; Oral health.
\end{abstract}

\section{Introduction}

Chronic kidney disease (CKD) is a systemic condition that adversely affects the patient's quality of life. If left untreated, it can progress to advanced stages, which are associated with high morbidity and mortality. The American Society of Nephrology defined CKD and classified it into five stages based on the glomerular filtration rate (GFR). ${ }^{1-3}$

Given the increasing prevalence of $\mathrm{CKD}$, there are ongoing attempts to identify and control the associated risk factors such as obesity, malnutrition, hypertension, diabetes mellitus, as well as periodontal diseases. Such attempts are imperative to decrease the burden of disease on CKD affected patients. ${ }^{4-7}$

It has been suggested that periodontitis was a potential independent risk factor for $\mathrm{CKD}{ }^{8}$ By definition, periodontitis is a chronic inflammatory condition that causes periodontal tissue destruction. It often occurs due to poor oral hygiene, microbial plaque, and calculus accumulation around the tooth surface causing subsequent gingival inflammation, periodontal pocket formation, and loss of tooth supporting structures. ${ }^{9}$ In this case, the local inflammatory factors and C-reactive protein (CRP) pass through the affected gingiva into the peripheral blood circulation and exert systemic effects. ${ }^{4,10}$ Continuation of this process in CKD patients can aggravate their disease condition and even it may lead to renal failure if left untreated. Based on a cross-sectional study, a mutual correlation was reported between periodontal diseases and CKD. ${ }^{11}$ Likewise, such correlations have been assumed between periodontal diseases and a number of other systemic conditions such as cardiovascular diseases, diabetes mellitus, osteoporosis, respiratory diseases, rheumatoid arthritis, low birth weight, and immature birth., ${ }^{42-19}$ In general, periodontitis is a multifactorial disease, and therefore, several factors are affecting the susceptibility and development of periodontal diseases..$^{20,21}$ The prevalence of periodontal disease has been reported 57\% in CKD patients. ${ }^{22}$ Thus, considering the role of periodontitis on systemic conditions, the purpose of this study was to assess the correlation between periodontal diseases and CKD duration.

\section{Materials and Methods}

This descriptive cross-sectional study was approved by the regional Research Ethics Committee with reference number "IR.SBMU.RIBS.REC.1394.170" and performed in complete accordance with the Declaration of Helsinki. Participation in this study was voluntary and written informed consent was obtained from all subjects. After explanation of the study objectives, potential questions were answered by the lead author. Likewise, oral examination was conducted by a single calibrated examiner (lead author) prior to their hospital appointments. A convenient sampling technique was used to recruit CKD adult patients who attended the "Labbafinejad Hospital" in Tehran city during 2017. For sample size calculation, we used the reported prevalence (57\%) with 95\% confidence level, and $7 \%$ margin of error. Based on this calculation, at least 192 cases were needed for conducting this study.

Two instruments were used for data collection in this project. The first questionnaire assessed the oral health behavior of CKD patients and it was a self-reported questionnaire. The second questionnaire was a standard WHO instrument which was used for clinical evaluation of the oral health status of CKD patients. Likewise, WHO recommended methodology was used for oral examination in order to determine the decayed, missing, and filled teeth (DMFT) in our sample population. For gingival health status, we used the clinical 
attachment loss (CAL), periodontal index (PI), community periodontal index (CPI), and oral hygiene index (OHI).

The CAL was used for measuring the position of the soft tissue in relation to the cemento-enamel junction (CEJ) which is a fixed point. Two measurements were used to calculate the CAL index: The probing depth and the distance from the gingival margin to the CEJ.

The PI was used by evaluating and scoring all teeth using five well-distinguished categories $(0,1,2,6$, and 8$)$, representing incremental degrees of disease severity.

The CPI was based on three features of bleeding, dental calculus, and depth of gingival sulcus. A special "WHOprobe" was used for periodontal examinations.

The OHI was reported as the sum of two indices; the amounts of debris, and calculus present on the tooth surface. Thus, the OHI may ranges from 0 , meaning no debris or calculus to as high as 6 . The debris index consists of the following scores: 0 , no debris on the tooth surface; 1 , less than onethird of tooth surface covered with soft debris; 2, more than one-third and less than two-thirds of tooth covered with soft debris; 3 , over two-thirds of the tooth surface covered with soft debris. Likewise, the calculus index, composed of the following scores: 0 , no calculus on the tooth surface; 1 , less than onethird of the tooth surface covered with supra-gingival calculus; 2 , over one-third and less than two-thirds of the tooth surface covered with supra-gingival calculus; 3 , over two-thirds of the tooth surface covered with supra-gingival calculus. ${ }^{12}$

For oral health behaviors evaluation, several questions were used to assess daily tooth brushing frequency, use of fluoridated toothpaste, flossing, consuming sugary snacks between main meals, frequency of dental visits per year, the time of last dental check-up, and cigarette smoking habit.

Data were collected anonymously and analyzed using SPSS version 22. The frequency of qualitative variables, and the mean and standard deviation of quantitative variables were reported for the sample population. Likewise, demographic variables, oral health-related behaviors and oral health-related indices were reported for CKD patients. The independent $t$-test, Mann-Whitney test, and Pearson correlation coefficient were used for statistical analysis. The P-value less than 0.05 was considered statistically significant.

\section{Results}

Out of 192 participants, $90(46.9 \%)$ patients were male and $102(53.1 \%)$ were female. The mean age of patients was 51.9 $( \pm 15.1)$ years, ranging from 18 to 79 years. The mean duration of CKD in patients was $7.70( \pm 7.34)$ years. Additional patients' demographic information was presented in Table 1 . The frequency distribution of patients' past dental experiences were provided in Table 2. Out of $67.7 \%$ of patients who experienced toothache in the past year, only $52 \%$ of them had a dental visit.

As reported in Table 3, A high percent of patients had gingival bleeding (67.7\%), more than half of the them had periodontal pocket higher than $4 \mathrm{~mm}$, and about $34 \%$ had CAL $>4 \mathrm{~mm}$ as reported in Table 4 .

The mean DMFT index was $11.61( \pm 6.23)$ (Table 4$)$. Gender differences in mean DMFT and periodontal index was minimal $(\mathrm{P}=0.99)$. However, advance state of periodontal diseases as demonstrated by CAL index, was slightly higher among female when compared with male CKD patients $(\mathrm{P}=0.87)$. Although, no significant association was detected

\begin{tabular}{|c|c|c|c|}
\hline Variable & Category & Number & Percentage \\
\hline \multirow[t]{2}{*}{ Gender } & Male & 90 & 46.9 \\
\hline & Female & 102 & 53.1 \\
\hline \multirow[t]{3}{*}{$\begin{array}{l}\text { Age groups } \\
\text { (yrs.) }\end{array}$} & $18-40$ & 46 & 23.9 \\
\hline & $41-60$ & 92 & 47.9 \\
\hline & $61-80$ & 54 & 28.2 \\
\hline \multirow[t]{2}{*}{$\begin{array}{l}\text { Place of } \\
\text { residence }\end{array}$} & Tehran & 138 & 71.9 \\
\hline & Other provinces & 54 & 28.1 \\
\hline \multirow[t]{4}{*}{$\begin{array}{l}\text { Educational } \\
\text { level }\end{array}$} & Illiterate & 22 & 11.5 \\
\hline & $\begin{array}{l}\text { Below high school } \\
\text { diploma }\end{array}$ & 74 & 38.5 \\
\hline & High school diploma & 61 & 31.8 \\
\hline & $\begin{array}{l}\text { Over high school } \\
\text { diploma }\end{array}$ & 35 & 18.2 \\
\hline \multirow[t]{3}{*}{$\begin{array}{l}\text { Disease } \\
\text { duration }\end{array}$} & $<5$ years & 85 & 44.3 \\
\hline & $5-10$ years & 49 & 25.5 \\
\hline & $\geq 10$ years & 57 & 29.7 \\
\hline \multirow{7}{*}{$\begin{array}{l}\text { Underlying } \\
\text { disease/ } \\
\text { health } \\
\text { conditions }\end{array}$} & Hypertension & 71 & 36.9 \\
\hline & Anemia & 40 & 20.8 \\
\hline & Diabetes mellitus & 30 & 15.6 \\
\hline & Cardiac disease & 30 & 15.6 \\
\hline & Liver disease & 30 & 2.1 \\
\hline & Cancer & 1 & 0.5 \\
\hline & None & 29 & 15.1 \\
\hline
\end{tabular}

between DMFT and PI with patients' education $(\mathrm{P}>0.05)$, but the prevalence of CAL $>4 \mathrm{~mm}$ and PI was higher among patients with lower education $(\mathrm{P}=0.12, \mathrm{P}=0.92)$.

As demonstrated in Table 5, a direct correlation was detected between duration of CKD and DMFT index ( $\mathrm{r}=0.64$, $\mathrm{P}<0.001)$ as well as the PI $(\mathrm{r}=0.48, \mathrm{P}<0.001)$. Also, a longer disease duration was detected in patients with $\mathrm{CAL}>4 \mathrm{~mm}$ $(\mathrm{P}=0.02)$.

\section{Discussion}

Several studies have reported on the correlation between periodontal diseases and CKD, emphasizing on the regular oral and dental care as one of the most important strategies to decrease the burden of CKD. ${ }^{23,24}$ In other words, entry of local inflammatory factors from affected gingiva into patient's blood stream can aggravate systemic inflammation process and exacerbate the CKD. Obviously, oral health is not only about optimal esthetics, mastication, phonetic, and speech; there is a direct and often mutual correlation between oral health and general health. Not paying enough attention to this critical 


\begin{tabular}{|c|c|c|c|}
\hline Variable & Score/Response & Number & Frequency \\
\hline \multirow[t]{4}{*}{ Oral complaints } & Bad taste in the mouth & 126 & 65.6 \\
\hline & Halitosis & 115 & 59.9 \\
\hline & Xerostomia & 114 & 59.4 \\
\hline & Oral ulcers & 55 & 28.6 \\
\hline \multirow{4}{*}{$\begin{array}{l}\text { Oral and dental } \\
\text { self-assessment }\end{array}$} & Good & 66 & 34.4 \\
\hline & Moderate & 65 & 33.8 \\
\hline & Poor & 53 & 27.6 \\
\hline & I do not know & 8 & 4.2 \\
\hline \multirow{4}{*}{$\begin{array}{l}\text { Gingival self- } \\
\text { assessment }\end{array}$} & Good & 84 & 42.7 \\
\hline & Moderate & 54 & 28.1 \\
\hline & Poor & 49 & 25.5 \\
\hline & I do not know & 7 & 3.6 \\
\hline \multirow[t]{5}{*}{ Tooth cleaning } & Tooth brushing & 185 & 96.4 \\
\hline & Dental flossing & 52 & 27.1 \\
\hline & Wooden toothpick & 21 & 19.9 \\
\hline & Plastic toothpick & 19 & 9.9 \\
\hline & Toothbrush stick & 4 & 2.1 \\
\hline \multirow{3}{*}{$\begin{array}{l}\text { Frequency of } \\
\text { daily tooth } \\
\text { brushing }\end{array}$} & Twice or more & 51 & 26.6 \\
\hline & Once & 79 & 41.1 \\
\hline & Less than one a day & 62 & 2.1 \\
\hline \multirow{4}{*}{$\begin{array}{l}\text { Frequency of } \\
\text { dental visits per } \\
\text { year }\end{array}$} & Twice or more & 17 & 8.8 \\
\hline & Once & 60 & 31.3 \\
\hline & Never & 113 & 58.9 \\
\hline & I do not know & 2 & 1 \\
\hline \multirow{4}{*}{$\begin{array}{l}\text { Time of last } \\
\text { dental visit }\end{array}$} & $<1$ year ago & 79 & 40.1 \\
\hline & Between 1-5 years ago & 87 & 45.6 \\
\hline & $\geq 5$ years ago & 24 & 12.6 \\
\hline & Never & 2 & 1 \\
\hline
\end{tabular}

\begin{tabular}{|c|c|c|c|}
\hline Variable & Score & Number & Percentage \\
\hline \multirow[t]{3}{*}{ DMFT } & $<10$ & 102 & 53.1 \\
\hline & $10-20$ & 72 & 37.5 \\
\hline & $>20$ & 18 & 9.4 \\
\hline \multirow[t]{3}{*}{ Gingival bleeding } & No bleeding & 60 & 31.3 \\
\hline & Bleeding & 130 & 67.7 \\
\hline & Edentulous & 2 & 1 \\
\hline \multirow[t]{3}{*}{ Periodontal pocket } & No pocket & 81 & 42.3 \\
\hline & 4-6 mm pocket & 109 & 56.7 \\
\hline & Edentulous & 2 & 1 \\
\hline \multirow{3}{*}{$\begin{array}{l}\text { Clinical attachment } \\
\text { loss }\end{array}$} & $0-3 \mathrm{~mm}$ & 126 & 65.6 \\
\hline & $4-5 \mathrm{~mm}$ & 61 & 31.8 \\
\hline & 6-8 mm & 5 & 2.6 \\
\hline \multirow[t]{4}{*}{ Debris index } & 0 & 48 & 25 \\
\hline & $>1 / 3$ & 111 & 57.8 \\
\hline & $1 / 3-2 / 3$ & 25 & 13 \\
\hline & $>2 / 3$ & 8 & 4.2 \\
\hline \multirow[t]{4}{*}{ Calculus index } & 0 & 37 & 19.3 \\
\hline & $>1 / 3$ & 95 & 49.5 \\
\hline & $1 / 3-2 / 3$ & 48 & 25 \\
\hline & $>2 / 3$ & 12 & 6.3 \\
\hline
\end{tabular}

DMFT: Decayed, Missing, and Filled Teeth

point, it can impose a significant financial burden on patients and the health-care system. Financial resources are important for financing public health plans for overall health promotion. However, most developing countries have excluded oral health from the list of their priorities due to budgetary constraints. This can cause several problems and exerts additional burden on patients and the health-care system. Thus, this study aimed to assess the correlation between periodontal disease and CKD duration in order to provide further information that may be useful for medical professionals and authorities, policy makers in the health-care systems in developing countries.

In 2016, Ausavarungnirun et al assessed the correlation between periodontal disease and different stages of CKD in

\begin{tabular}{|c|c|c|c|c|c|c|c|c|}
\hline & & DMFT & & PI & & $\mathrm{CAL}<4 \mathrm{~mm}$ & CAL $>4 \mathrm{~mm}$ & \\
\hline & & mean (SD) & Daice & mean (SD) & vaice & n (\%) & n (\%) & 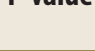 \\
\hline \multirow{2}{*}{ Gender } & Male & $11.63(6.17)$ & \multirow{2}{*}{0.99} & $1.43(0.92)$ & \multirow{2}{*}{0.99} & $58(65.2 \%)$ & 31 (34.8\%) & \multirow{2}{*}{0.87} \\
\hline & Female & $11.64(6.31)$ & & $1.43(0.88)$ & & $67(66.3 \%)$ & $34(33.7 \%)$ & \\
\hline \multirow{2}{*}{$\begin{array}{l}\text { Education } \\
\text { Level }\end{array}$} & Under diploma & $11.57(6.34)$ & \multirow{2}{*}{0.75} & $1.43(0.91)$ & \multirow{2}{*}{0.92} & $98(63.2 \%)$ & 57 (36.8\%) & \multirow{2}{*}{0.12} \\
\hline & Over diploma & $11.94(5.84)$ & & $1.42(0.87)$ & & $27(77.1 \%)$ & $8(22.9 \%)$ & \\
\hline
\end{tabular}

DMFT (Decayed, Missing, and Filled Teeth); PI (Periodontal Index); CAL (Clinical Attachment Loss); P-value (Probability value).

Level of significance: $P<0.05$ significant. 


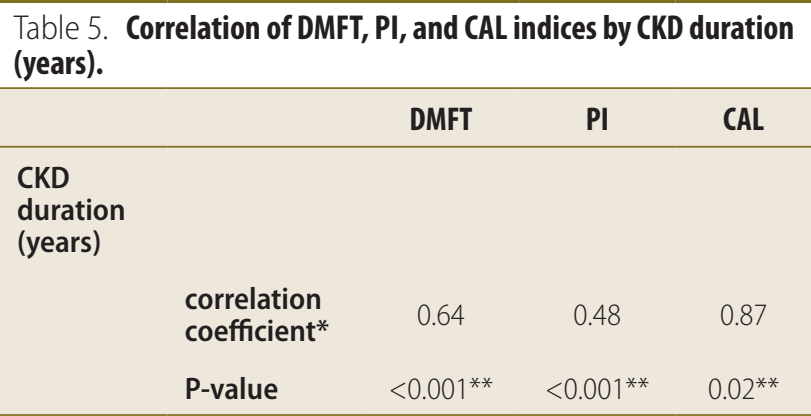

DMFT (Decayed, Missing, and Filled Teeth); PI (Periodontal Index);

CAL (Clinical Attachment Loss); CKD (Chronic Kidney Disease);

P-value (Probability value)

* Calculated by Pearson correlation coefficient.

** Level of significance: $\mathrm{P}<0.05$ significant.

Thai patients. They found that advanced periodontitis was more common in higher stages of CKD than early stages of disease. ${ }^{25}$ Also, Grubbs et al in a retrospective cohort study in 2016 evaluated the correlation between periodontal disease and kidney function and found that, the incidence of CKD was doubled in patients with advanced periodontitis. ${ }^{26}$ Grubbs et al in 2015 evaluated the correlation of periodontal disease (in different severities) with the occurrence of CKD in AfricanAmericans and reported that patients with advanced periodontitis were four times more susceptible to CKD ( $\mathrm{P}=0.002)$. They showed that periodontal diseases were more common in patients at high risk of $\mathrm{CKD}$, and found a significant correlation with clinical impairment of renal function. ${ }^{8}$ In their study, $86.3 \%$ of patients had gingival bleeding and $29.8 \%$ had pocket depth $>4 \mathrm{~mm}$. Also, CAL $>4 \mathrm{~mm}$ was noted in $33.8 \%$ of patients. ${ }^{8}$ In present study, $67.7 \%$ of patients had gingival bleeding and $34.4 \%$ had CAL $>4 \mathrm{~mm}$. Also, $56.7 \%$ of patients had pocket depth $>4 \mathrm{~mm}$. Thus, the majority of our findings are in agreement with the results of Grubbs et al. ${ }^{8}$

In the same study, smoking had a significantly higher frequency among patients with advanced periodontitis. ${ }^{8}$ Thus, they concluded that smoking was an aggravating factor for periodontitis. In present study, the majority of patients were non-smokers; this probably explains why some periodontal indices such as PI in our patients were not as high as those reported in other studies. A review study by Ismail et al in 2013 reported higher prevalence of moderate to severe periodontal diseases in CKD patients compared with healthy controls. Likewise, they reported that periodontitis was correlated with higher level of systemic pro-inflammatory markers. ${ }^{27}$ In another review study by Ioannidou et al in 2013, the prevalence of periodontitis was assessed in CKD patients. In line with findings of other studies, this report also indicated higher prevalence of periodontitis in patients with CKD compared with healthy individuals. Moreover, increased prevalence of periodontitis was associated with decreased renal function in patients with CKD. ${ }^{28}$ Joseph et al in 2009 evaluated the prevalence of periodontal disease in CKD patients in comparison with healthy controls. They compared the oral hygiene, gingival inflammation, periodontal pocket, and CAL in 77 CKD patients with different etiologies and 77 healthy controls. The patients were divided into four groups of no periodontitis, mild, moderate, and severe periodontitis. They reported significantly higher periodontal indices in the CKD group compared with the control group. Also, the prevalence and severity of periodontal diseases were significantly higher in the CKD group $(\mathrm{P}<0.001) .{ }^{29}$

In present study, when comparing periodontal parameters measured in CKD patients with the national data, it was revealed that, most indices in $\mathrm{CKD}$ patients were considerably different from the national mean values reported by the latest National Oral Health Survey conducted in 2012..$^{30}$ Based on WHO recommendations, in this survey, three children and two adult age groups were considered. Therefore, our data were compared with national average in two adult age groups of 35-44 and 65-74 years old. The majority of our study participants fall within these two age categories $(18-40=24 \%$, $41-60=50 \%, 61+=28 \%$ ). Although, patients' age in our study population was slightly younger than the mean age of patients in the national survey, the measured indices were found to be higher than the national average.

One limitation of this study can be improved by using multicenter design and make further assessments in order to determine if prevention and treatment of periodontal diseases can prevent GFR decline in CKD patients.

\section{Conclusion}

Given the direct correlation between the periodontal conditions and duration of $\mathrm{CKD}$, regular biannual dental visits are essential for CKD patients. All physicians are encouraged to include regular oral health check-ups in the treatment protocol for CKD patients. Thus, the active cooperation between medical and dental teams can be helpful in minimizing the CKD progression and severity.

\section{Financial support and sponsorship}

Nil.

\section{Conflicts of interest}

There are no conflicts of interest.

\section{A list of abbreviations}

CKD: Chronic kidney disease

CAL: Clinical attachment loss

PD: Pocket depth

PI: Periodontal index

DMFT: Decayed, missing, and filled teeth

GFR: Glomerular filtration rate

CEJ: Cementoenamel junction

CPI: Community periodontal index

WHO: World Health Organization

\section{References}

1. Levey AS, Coresh J, Bolton K, Culleton B, Harvey KS, Ikizler TA, et al. KJ $\mathrm{DOQ}$ I clinical practice guidelines for chronic kidney disease: evaluation, classification, and stratification. National Kidney Foundation. Am J Kidney Dis 2002;39:1-266.

2. Rosansky, SJ. Renal function trajectory is more important than chronic kidney disease stage for managing patients with chronic kidney disease. Am J Nephrol 2012;36:1-10.

3. Khajehdehi P, Malekmakan L, Pakfetrat M, Roozbeh J, Sayadi M. Prevalence of chronic kidney disease and its contributing risk factors in southern 
Iran: a cross-sectional adult population-based study. Iran J Kidney Dis 2014:8:109-15

4. Han SS, Shin N, Lee SM, Lee H, Kim DK, Kim YS. Correlation between periodontitis and chronic kidney disease in Korean adults. Kidney Res Clin Pract 2013;32:164-70

5. Hakemi MS. Chronic kidney disease epidemiology. Iran J Kidney Dis 2014;8:261.

6. Kshirsagar AV, Moss KL, Elter JR, Beck JD, Offenbacher S, Falk RJ. Periodontal disease is associated with renal insufficiency in the Atherosclerosis Risk; In Communities (ARIC) study. Am J Kidney Dis 2005;45:650-57.

7. Fisher MA, Taylor GW, Shelton BJ, Jamerson KA, Rahman M, Ojo AO, et al. Periodontal disease and other nontraditional risk factors for CKD. Am J Kidney Dis 2008:51:45-52.

8. Grubbs V, Vittinghoff E, Beck JD, Kshirsagar AV, Wang W, Griswold ME, et al. Association between periodontal disease and kidney function decline in African Americans: The Jackson Heart Study. J Periodontol 2015;86:1126-32.

9. Armitage GC. Development of a classification system for periodontal diseases and conditions. Ann Periodontol 1999:4:1-6.

10. Arigbede AO, Babatope BO, Bamidele MK. Periodontitis and systemic diseases: A literature review. J Ind Soc Periodontol 2012;16:487-91.

11. Ricardo AC, Athavale A, Chen J, Hampole H, Garside D, Marucha P, et al. Periodontal disease, chronic kidney disease and mortality: results from the third National Health and Nutrition Examination Survey. BMC Nephrol 2015;16:97.

12. Butchibabu Kalakonda D, Koppolu P, Kusai Baroudi D, Mishra A. Periodontal systemic connections-novel associations-a review of the evidence with implications for medical practitioners. Int J Health Sci 2016;10:293-307.

13. Joshy G, Arora M, Korda RJ, Chalmers J, Banks E. Is poor oral health a risk marker for incident cardiovascular disease hospitalisation and all-cause mortality? Findings from 172630 participants from the prospective 45 and Up Study. BMJ Open 2016:6:e012386.

14. Broder HL, Tormeti D, Kurtz AL, Baah-Odoom D, Hill RM, Hirsch SM, et al. Type II diabetes and oral health: perceptions among adults with diabetes and oral/health care providers in Ghana. Community Dent Health 2014;31:158-62.

15. Jeffcoat M, Parry S, Sammel M, Clothier B, Catlin A, Macones G. Periodontal infection and preterm birth: successful periodontal therapy reduces the risk of preterm birth. BJOG Int J Obstet Gynaecol 2011;118:250-6.

16. Haerian-Ardakani A, Eslami Z, Rashidi-Meibodi F, Haerian A, Dallalnejad P, Shekari M, et al. Relationship between maternal periodontal disease and low birth weight babies. Iran J Reprod Med 2013;11:625-30.
17. Esfahanian V, Sadighi Shamami MZ, Sadighi Shamami MH. Relationship between osteoporosis and periodontal disease: review of the literature. J Dent (Tehran) 2012;9:256-64.

18. Venkataraman A, Almas K. rheumatoid arthritis and periodontal disease. an update. NY State Dent J 2015;81:30-6.

19. Kim HD, Sim SJ, Moon JY, Hong YC, Han DH. Association between periodontitis and hemorrhagic stroke among Koreans: a case-control study. J Periodontol 2010;81:658-65.

20. Ruospo M, Palmer SC, Craig JC, Gentile G, Johnson DW, Ford PJ, et al. Prevalence and severity of oral disease in adults with chronic kidney disease: a systematic review of observational studies. Nephrol Dia Transplant 2014;29:364-75.

21. Kawar N, Gajendrareddy PK, Hart TC, Nouneh R, Maniar N, Alrayyes S. Periodontal disease for the primary care physician. Dis Mon 2011;57:174-83.

22. Brito F, Almeida S, Figueredo CM, Bregman R, Suassuna JH, Fischer RG. Extent and severity of chronic periodontitis in chronic kidney disease patients. J Periodontal Res 2012;47:426-30.

23. Craig RG. Interactions between chronic renal disease and periodontal disease. Oral Dis 2008;14:1-7.

24. Wahid A, Chaudhry S, Ehsan A, Butt S, Ali Khan A. Bidirectional relationship between chronic kidney disease \& periodontal disease. Pak J Med Sci 2013;29:211-5.

25. Ausavarungnirun R, Wisetsin S, Rongkiettechakorn N, Chaichalermsak S, Udompol U, Rattanasompattikul M. Association of dental and periodontal disease with chronic kidney disease in patients of a single, tertiary care centre in Thailand. BMJ Open 2016;6:e011836.

26. Grubbs V, Vittinghoff E, Taylor G, Kritz-Silverstein D, Powe N, BibbinsDomingo K, et al. The association of periodontal disease with kidney function decline: a longitudinal retrospective analysis of the MrOS dental study. Nephrol Dial Transplant 2016;31:466-72.

27. Ismail G, Dumitriu HT, Dumitriu AS, Ismail FB. Periodontal disease: a covert source of inflammation in chronic kidney disease patients. Int J Nephrol 2013;2013:1-6.

28. Ioannidou E, Hall Y, Swede H, Himmelfarb J. Periodontitis associated with chronic kidney disease among Mexican Americans. J Public Health Dent 2013;73:112-9.

29. Joseph R, Krishnan R, Narayan V. Higher prevalence of periodontal disease among patients with predialytic renal disease. Braz J Oral Sci 2009:8:14-8

30. Khoshnevisan M.H, Ghasemianpour M, Samadzadeh H, Baez RJ. Oral health status and healthcare system in I.R. Iran. J Contemp Med Sci 2018:4:107-18. 